Article

\title{
A Clamping Force Performance Evaluation of the Electro Mechanical Brake Using PMSM
}

\author{
Seung-Koo Baek *, Hyuck-Keun Oh, Seog-Won Kim and Sung-Il Seo \\ Department of Next Generation Railroad Train Research Center, Korea Railroad Research Institute, 176, \\ Cheoldo Bangmulgwan-ro, Uiwang-si, Gyeonggi-Do 437-757, Korea; hkoh@krri.re.kr (H.-K.O.); \\ swkim@krri.re.kr (S.-W.K.); siseo@krri.re.kr (S.-I.S.) \\ * Correspondence: skbaek@krri.re.kr; Tel.: +82-31-460-5507
}

Received: 11 September 2018; Accepted: 17 October 2018; Published: 24 October 2018

\begin{abstract}
This paper deals with clamping force simulation and experimental result of the Electro Mechanical Brake (EMB) for the High-Speed-Train (HST). Three phase Surface Permanent Magnet Synchronous Motor (SPMSM) is applied to the clamping force control of EMB. At the initial development stage, Proportional Integral (PI) current control under synchronous d-q axis frame was applied to the SPMSM torque control. In addition, an anti-windup controller, which is advantageous for fast current tracking, is proposed to improve the torque output. Matlab/Simulink simulation results were compared with the experimental results measured by the clamping force sensors of the EMB test rig. The experimental results were verified compared to the brake design specification of the High-Speed Electric Multiple Unit-430 Experimental (HEMU-430X) train.
\end{abstract}

Keywords: Brake-By-Wire (BBW); Electro Mechanical Brake (EMB); Surface Permanent Magnet Synchronous Motor (SPMSM); inverter; High-Speed-Train (HST)

\section{Introduction}

Due to the problems of hydraulic brakes with respect to the maintenance of oil and oil pressure lines, as well as the efficiency of hydraulic pump operation in conventional brake systems in the automotive field, EMB is drawing more attention [1,2].

At the initial stage of the development of EMB, a wedge brake structure was used for the generation of maximum clamping force in the caliper under a low input voltage of $12 \mathrm{Vdc}$. However, a great deal of research into electric vehicles has made it possible to use $42 \mathrm{Vdc}$ input voltage to achieve brake control of the caliper in the vertical direction of the brake disc directly [3].

There have been numerous studies on motor control methods that address clamping force control, including PI controller using basic control of current and speed under vector control [4], control of clamping force using a sliding mode controller [5], adaptive sliding mode control using a neural network to estimate [6], estimation methods of clamping force considered as gear friction [7], estimated control of clamping force using the rotor position due to impossible applications of force sensors based on the spatial constraints of the driving part [8,9], observer-based sensor-less robust force control methods [10], and fault diagnosis and tolerant control techniques based on the failure of the sensor [11-16]. Despite the number of studies, challenges still remain in terms of improving the safety requirements in automotive field, as well as the aspect of increasing costs of the entire braking system due to the complexity of the control system in comparison with hydraulic systems.

Studies are being actively conducted in the field of the railroad, such as the increase of transportation capacity and the upgrade of performance and miniaturization. In terms of the braking system, which is an important component of a train, applying EMB to the brake system is drawing attention as an alternative to existing pneumatic braking systems. EMB can decrease the volume of 
the entire braking system by up to $50 \%$ by eliminating the air compressor, air container for braking, piping for braking, valves, etc., which unnecessarily take up space at the bottom of the train, while it can also perform high-precision braking control and reduce latency time through fast response control. In addition, it is possible to design a structure that allows the brakes installed on different axles to share the braking force, even if one or more brakes breaks down. In Europe, an electric motor-type combined with a spring, called the Spring Loaded Brake System (SLBS) driving system, was developed and applied to low-speed light rail vehicles such as trams and monorails. In Korea, EMB clamping force performance had been tested by replacing the pneumatic braking part with the caliper, and was applied in urban railway vehicles with electric mechanical systems [17]. However, this mechanical torque transmission structure used ball screw-type transmission, which is different from the spur gear and camshaft-type transmission used in this paper.

This research study involves the simulation and experimental results of the EMB system. The output clamping force of the caliper, the braking force of the EMB system, and decelerating performance are predicted in an analytical approach using a Matlab/Simulink simulation, and the simulation results are compared with experimental results measured by the clamping force sensors of the EMB test rig. In addition, it is proposed to add an anti-windup controller to improve the PI current control and maximum clamping force performance for the control of output torque. The experimental results showed that the brake design specification of HEMU-430X can be satisfied, ensuring the possibility of applying EMB system to trains.

\section{Construction of EMB}

Figure 1 shows the EMB concept applied to the pneumatic brake of the HEMU-430X, a train being test run in Korea. The rotational torque generated at the motor, which is connected to the drive shaft, is transmitted to the cam shaft of the caliper by the ratio of the reduction gear. The pads connected with Lever 1 and 2 are moved to the brake disk to generate clamping force at the brake disk. The braking force generated at that moment is transmitted to the wheel of the train to activate the brakes. The motor used for the rotation of the driving shaft is the SPMSM, and Table 1 depicts the specifications of the SPMSM.

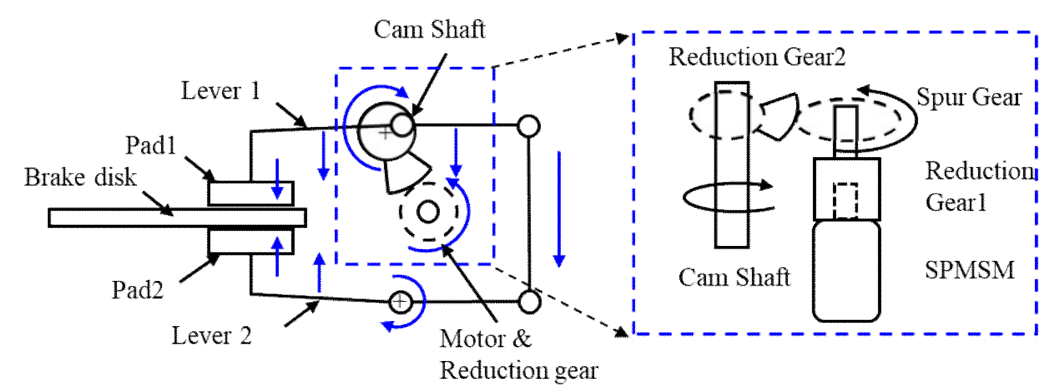

Figure 1. EMB concept for application to the pneumatic brake caliper of HEMU-430X.

Table 1. SPMSM Specification.

\begin{tabular}{cc}
\hline \multicolumn{2}{c}{ Motor Specification } \\
\hline Output Power & $600 \mathrm{~W}$ \\
Rated Speed & $3000 \mathrm{rpm}$ \\
Inductance $\left(L_{d}, L_{q}\right)$ & $0.744 \times 10^{-3} \mathrm{H}$ \\
Torque Constant & $0.25 \mathrm{Nm} / \mathrm{A}$ \\
Rated Torque & $1.9 \mathrm{Nm}$ \\
Number of Phase & 3 \\
Number of Poles & 8 \\
Number of Slots & 12 \\
Weight & $2.37 \mathrm{~kg}$ \\
\hline
\end{tabular}




\section{Simulation Results of the EMB System}

SPMSM mathematical modeling is necessary for the vector control simulation using Matlab/Simulink (R2018a, The MathWorks, Inc., Natick, MA, USA). The voltage equation of the synchronous d-q axis frame for SPMSM can be expressed as [18]:

$$
\begin{gathered}
v_{d s}^{r}=R_{s} i_{d s}^{r}+L_{d} \frac{d i_{d s}^{r}}{d t}-\omega_{r} L_{q} i_{q s}^{r} \\
v_{d s}^{r}=R_{s} i_{q s}^{r}+L_{q} \frac{d i_{q s}^{r}}{d t}+\omega_{r}\left(L_{d} i_{d s}^{r}+\phi\right)
\end{gathered}
$$

where $\omega_{r}$ is angular velocity, $R_{s}$ is resistance of stator, $L_{d}$ and $L_{q}$ are d-q axis inductance of stator, $i_{d s}^{r}$ and $i_{q s}^{r}$ are synchronous d-q axis current of stator, $\phi$ is flux linkage.

From Equations (1) and (2), the output torque of SPMSM can be expressed as:

$$
T_{\text {out }}=\frac{P}{2} \frac{3}{2}\left[\phi i_{q s}^{r}+\left(L_{d}-L_{q}\right) i_{d s}^{r} i_{q s}^{r}\right]
$$

From Equation (3), because of the mechanical structure of SPMSM, the d-q axis inductance $L_{d}$ and $L_{q}$ are designed with the same value, as shown in Table 1 . Therefore, the SPMSM has no reluctance torque and the d-axis current $i_{d s}^{r}$ has no impact on the output torque. Finally, output torque is defined as follows:

$$
T_{\text {out }}=\frac{P}{2} \frac{3}{2} \phi i_{q s}^{r}
$$

where $P$ is number of poles.

Figure 2 shows the relationship between current vector and output torque from Equations (3) and (4). From Figure 2, SPMSM can be controlled with minimum current when $i_{d s}^{r}$ is zero and all stator current input $I_{s}$ is controlled by $i_{q s}^{r}$.

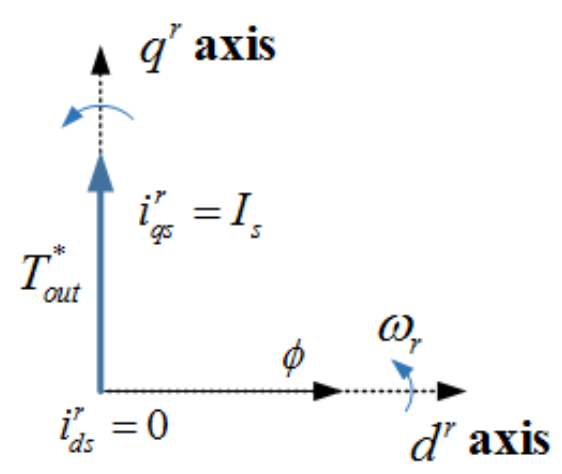

Figure 2. d-q axis current for vector control of SPMSM.

The mechanical part of Matlab/Simulink is constructed based on Figure 3b. The mechanical clamping force and the braking characteristics of EMB can be predicted analytically. A Train Brake Model (TBM) block is constructed using a Shoe Brake for the modeling, similar to the caliper structure in Figure 1. The torque output of the motor and reduction gear ass'y generated in Figure 3a is used as an input of TBM that consists of the wheel and axle ass'y. If the wheel and axle ass'y moves at a certain constant velocity, the braking force, braking distance and deceleration speed can be predicted during the motor torque input. However, because Matlab/Simulink cannot implement a motor stall operation in the braking state, the output torque is used as an input value of TBM as the motor is rotated in the normal state. 


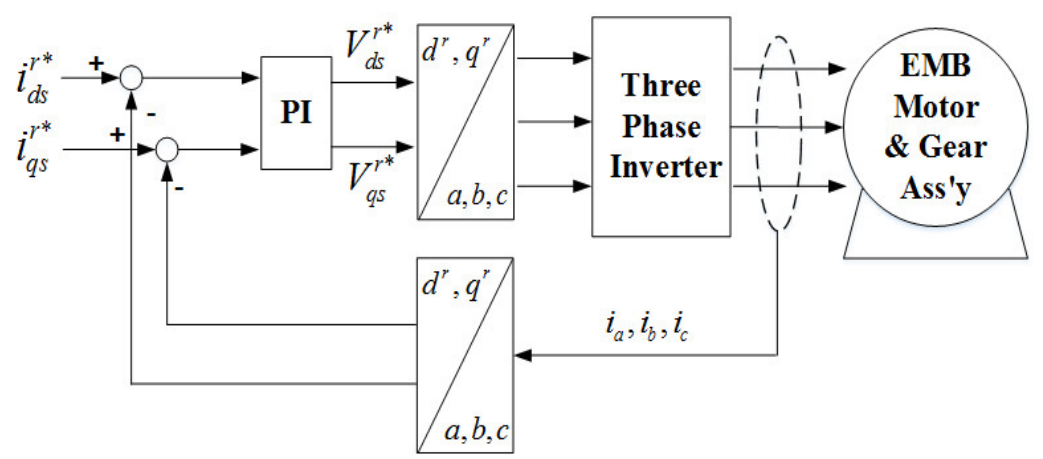

(a)

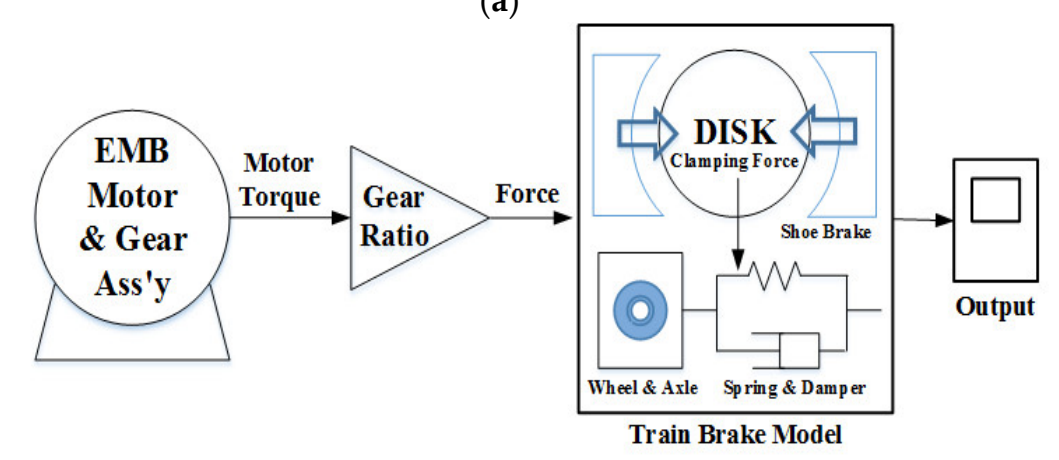

(b)

Figure 3. Simulation concept of EMB for Matlab/Simulink: (a) SPMSM current control concept diagram for EMB control; (b) train brake model for mechanical parts.

Figure 4 shows the wave form of current control of the d-q axis for the SPMSM. The standard current values of the $\mathrm{q}$ axis and the $\mathrm{d}$ axis are entered as $10 \mathrm{~A}$ and $0 \mathrm{~A}$, respectively, and it is shown that both $\mathrm{d}$-q axis follow the reference value within $40 \mathrm{~ms}$.

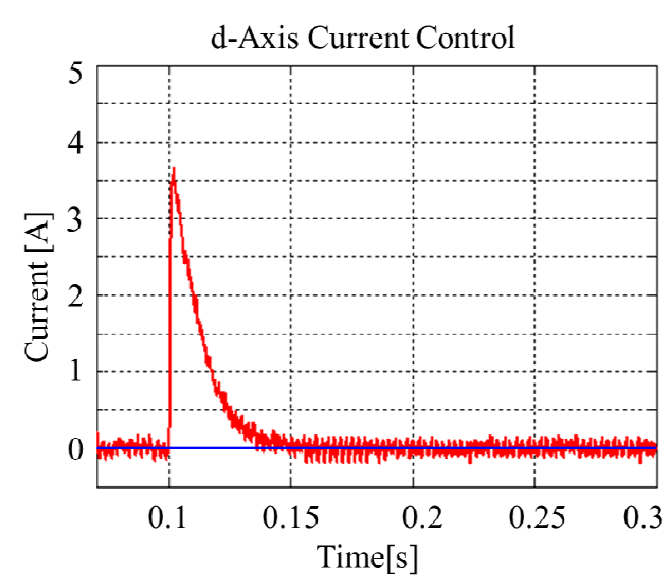

(a)

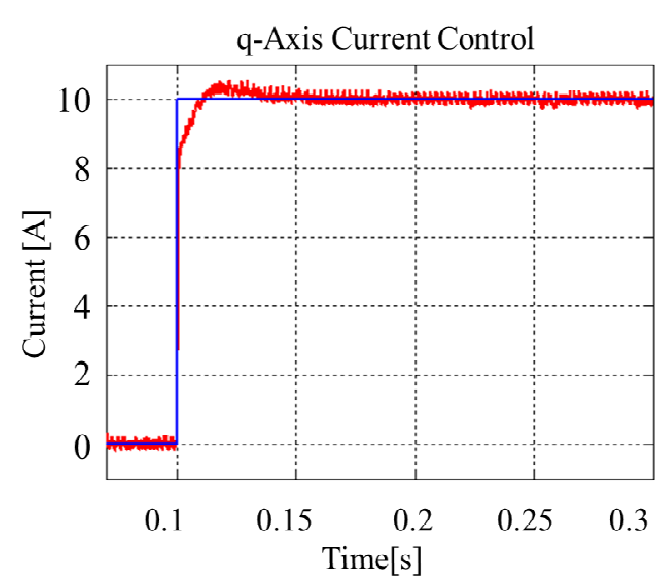

(b)

Figure 4. Simulation results for current control: (a) d-axis; (b) q-axis.

Figure 5a shows the torque output value of the motor according to the reference current value of the q-axis, and Figure $5 \mathrm{~b}$ shows the clamping force output value generated in the mechanical modeling by the reduction ratio between the first reduction gear and the second reduction gear from Figure 1 . The output rotating torque value of the motor is $1.75 \mathrm{Nm}$ at a q-axis input current reference of $10 \mathrm{~A}$, and the clamping force of the pad at this time is $51.5 \mathrm{kN}$. 


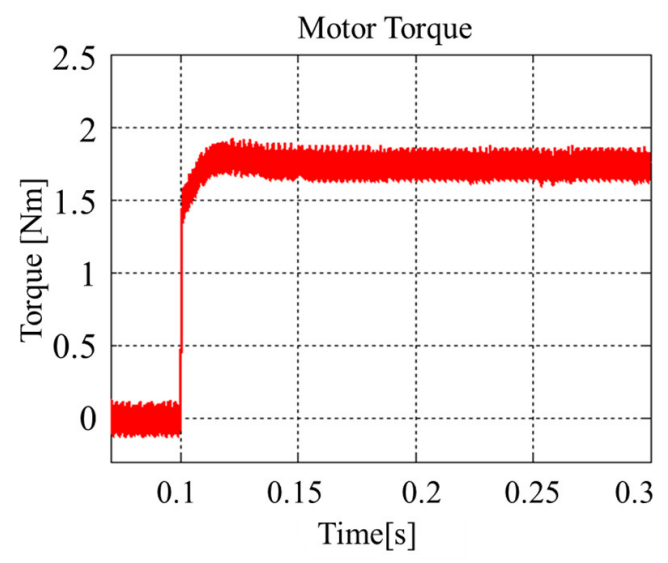

(a)

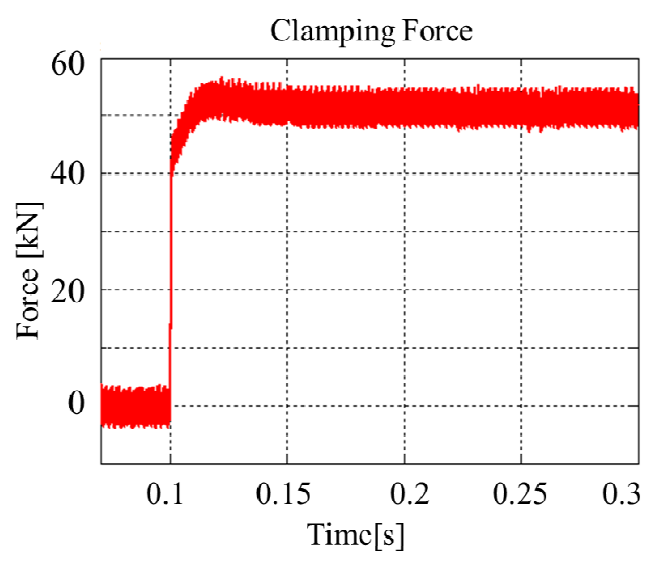

(b)

Figure 5. Simulation results for current control: (a) torque output from SPMSM; (b) clamping force from caliper.

Figure 6 shows the output results of the deceleration speed and braking force calculated in the TBM in Figure 3. Deceleration speed is calculated assuming that the wheel and axle in the TBM of $10 \mathrm{~kg}$ moves at a constant initial velocity of $300 \mathrm{~km} / \mathrm{h}$ during the simulation time. Figure 6 shows that the brake is activated within $0.2 \mathrm{~s}$, and the wheel and axle stop after moving a distance of $12 \mathrm{~m}$. The braking force at that moment is $10.4 \mathrm{kN}$. Braking force can be converted to clamping force per caliper and expressed as:

$$
C F_{\text {caliper }}=B F_{\text {system }} /\left(D \times F_{r}\right)=10.4 \mathrm{kN} /(0.667 \times 0.3)=51.97 \mathrm{kN}
$$

where $C F_{\text {caliper }}$ is clamping force per caliper, $B F_{\text {system }}$ is braking force of system, $D$ is effective diameter ratio, and $F_{r}$ is coefficient of friction. According to Figure $5 \mathrm{~b}$, braking force output of TBM can be verified from Equation (5).

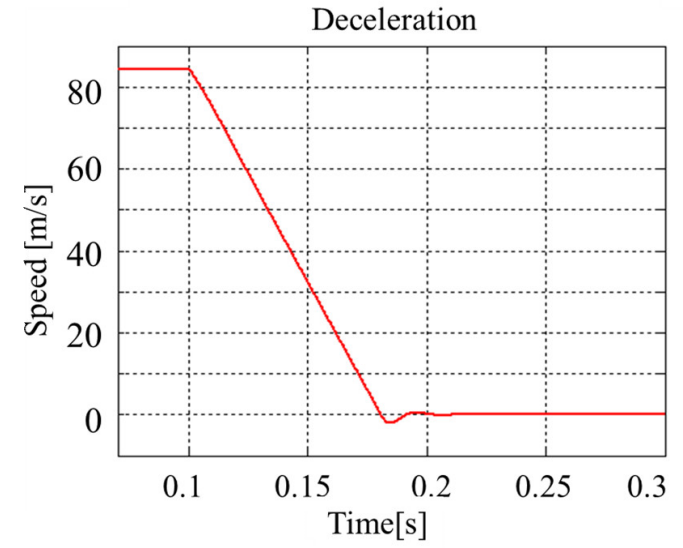

(a)

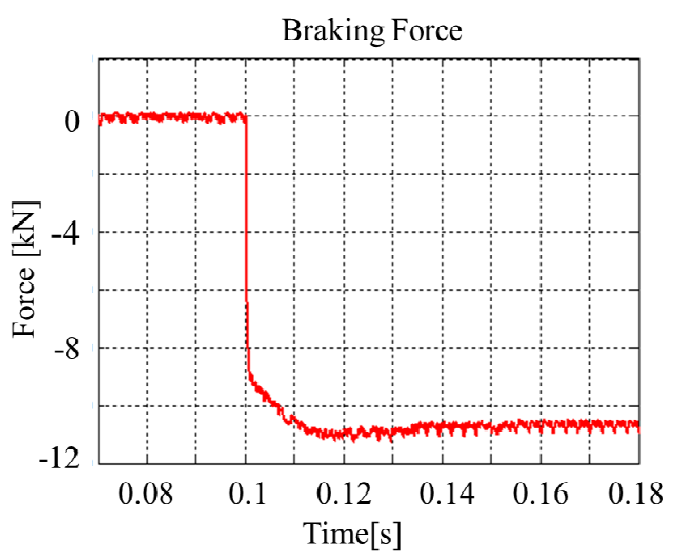

(b)

Figure 6. Simulation results for mechanical brake block: (a) deceleration speed; (b) braking force.

\section{Experimental Results of the EMB system}

Figure 7 shows the installation of the EMB test rig for the performance test. The experimental results from the EMB test rig are compared with the Matlab/Simulink simulation results in order to verify the EMB performance. Figure $7 \mathrm{~b}$ shows the EMB applied to the caliper, which is the same type as the pneumatic brake of the HEMU-430X, as shown in Figure 1. Measurement of clamping force was performed by removing pads from both sides of the caliper in which the braking pads were installed and attaching two equivalent sensors (Loadcell). The specifications of the sensor for the 
measurement of clamping force are shown in Table 2. The output of the Loadcell is measured by converting to voltage through an amplifier. The maximum clamping force and the response time to reach the maximum clamping force were recorded by the output waveform from the scope.

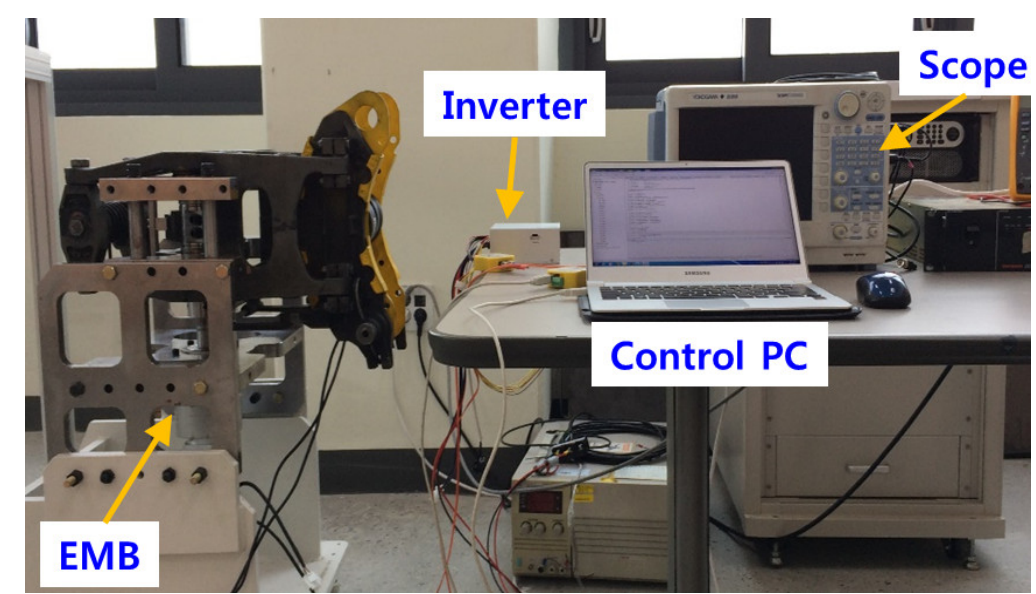

(a)

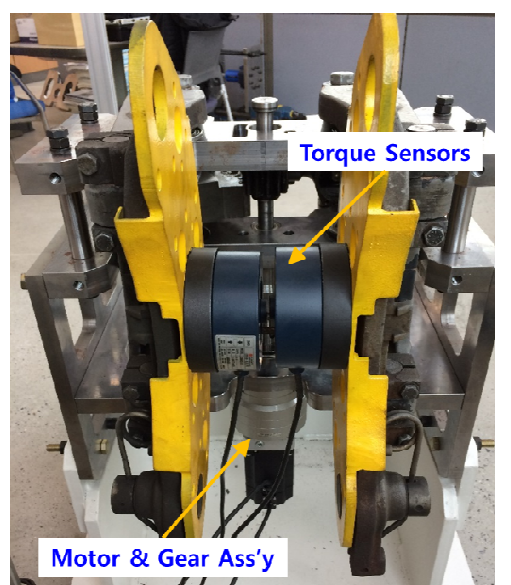

(b)

Figure 7. Installation for the EMB performance test rig: (a) system installation; (b) parts of caliper.

Table 2. Loadcell specifications.

\begin{tabular}{cc}
\hline \multicolumn{2}{c}{ Loadcell Specifications } \\
\hline Rated Output & $2.0 \pm 0.005 \mathrm{mV} / \mathrm{V}$ \\
Excitation Voltage & $\pm 10 \mathrm{Vdc}$ \\
Zero Balance & $0.0 \pm 0.02 \mathrm{mV} / \mathrm{V}$ \\
Accuracy & $\pm 0.02 \%$ \\
Resistance (Input/Output) & $350 \pm 3.5 \Omega$ \\
\hline
\end{tabular}

Figure 8 shows the experimental clamping force results for the conventional pneumatic brake installed in the HEMU-430X. The clamping force was measured with the sensor installed as shown in Figure $7 \mathrm{~b}$ by injecting the same pneumatic pressure as that of an actual vehicle. At that time, no overshoot occurred in the transient response. The response time from the initial zero clamping force to the maximum clamping force was $900 \mathrm{~ms}$, and the maximum clamping force was $51.3 \mathrm{kN}$. When the brake is actuated, the occurrence of overshoot has a bad effect on ride comfort for passengers, caused by jerk. In this paper, SPMSM control was done by minimizing the overshoot in the transient response characteristic of the EMB system, and experimental results were compared with the pneumatic braking system.

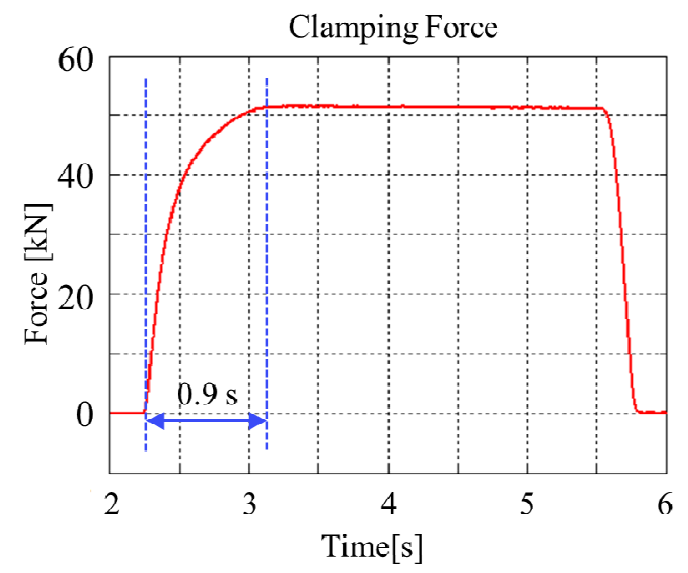

Figure 8. Clamping force experimental results for the pneumatic brake system of the HEMU-430X. 
Figure 9 shows the reference values for emergency braking in accordance with the speed of the HEMU-430X. As shown in Figure 9, maximum braking force occurs at $110 \mathrm{~km} / \mathrm{h}$ in each vehicle. The reference value for maximum braking force at that time was determined to be $54 \mathrm{kN}$. Compared to the experimental values in Figure 8, there was an error of about $5 \%$ at the maximum clamping force.

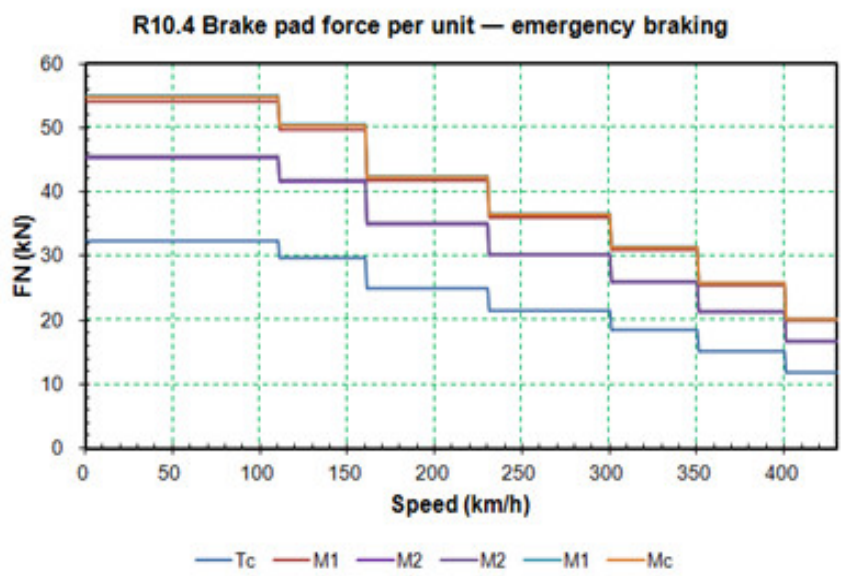

Figure 9. Clamping force design specifications for emergency braking for the HEMU-430X.

Figure 10a shows the experimental clamping force waveform of the EMB. As mentioned above in the previous section, the q-axis current was applied to control EMB. As shown in Figure 8, to generate similar output clamping force to the pneumatic brake, the reference current value of q-axis was set at $10 \mathrm{~A}$. The gain of the PI current controller was set in order not to generate overshoot. At that time, the transient response time to reach the maximum clamping force was $410 \mathrm{~ms}$, and the maximum clamping force was measured at about $51.8 \mathrm{kN}$. Compared to the pneumatic system, the transient response time to reach the maximum clamping force was faster by more than $50 \%$. There was an error in output torque that was within 1\% compared to the result of the simulation in Figure 5. From Equation (6), when the current of the q-axis is applied to $10 \mathrm{~A}$, the motor output torque is $1.75 \mathrm{Nm}$, and if the reduction gear ratio is considered, the motor output torque is $1.7547 \mathrm{Nm}$, based on the experiment results of a clamping force of $51.8 \mathrm{kN}$. This shows that the calculation torque and the experimental torque values are almost the same.

$$
T_{\text {out }}=i_{q s}^{r} \times\left(1.5 \times P_{n} \times \phi\right)=i_{q s}^{r} \times 0.175
$$

where $P_{n}$ is pole pair.

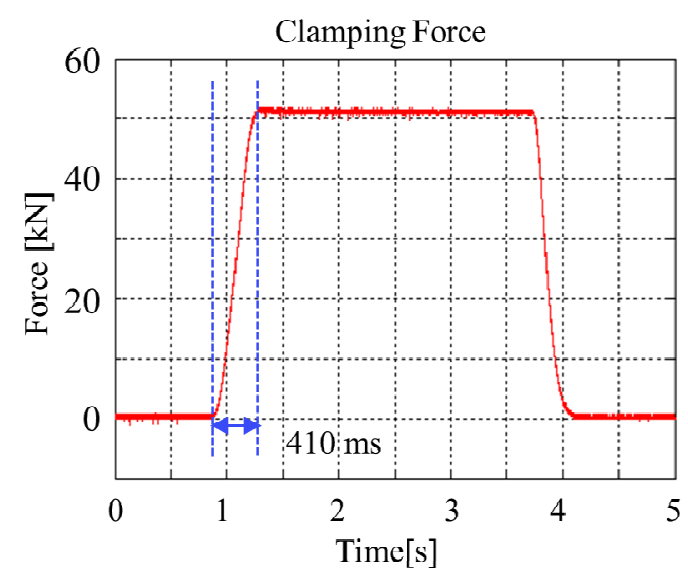

(a)

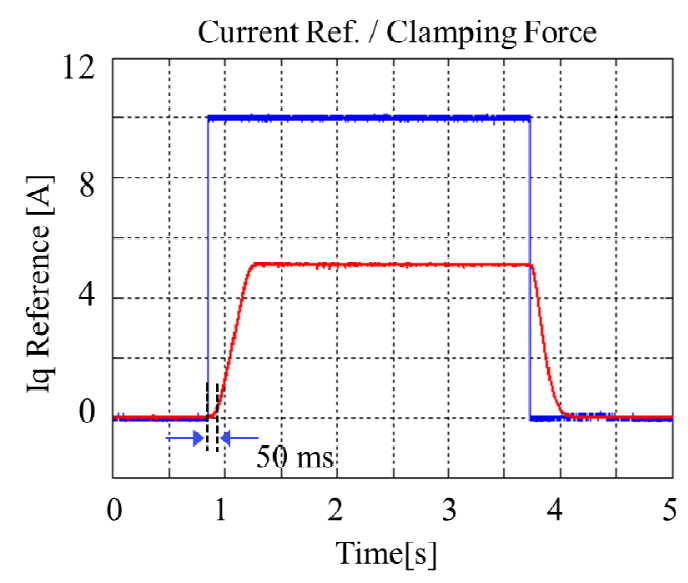

(b)

Figure 10. EMB experimental results: (a) clamping force; (b) response time of the clamping force. 
Figure 10b shows the transient response time in accordance with the clamping force reference input. After the synchronous current reference input of the q-axis is applied, the clamping force of the EMB occurs within $50 \mathrm{~ms}$. In addition, the total time of $450 \mathrm{~ms}$ is measured until the occurrence of maximum clamping force. The EMB shows about a $2.5 \mathrm{~s}$ faster response time than the conventional pneumatic brake system, which has a latency time of about $3 \mathrm{~s}$. This shows that the reduction of the braking distance is about $200 \mathrm{~m}$, in the case of a train running at a speed of $300 \mathrm{~km} / \mathrm{h}$.

Figure 11a shows the synchronous current control experimental result of q-axis in SPMSM. When the q-axis current of $10 \mathrm{~A}$ is applied to the motor and the motor stall occurs, at that time, the motor current increases rapidly under the brake pads and cannot move any more. However, the q-axis output current tracks stably to the reference current. In the case of the current control simulation results in Figure 5, because Matlab/Simulink simulation uses the motor output torque under a normal rotation state, the waveform of the q-axis current control is different from EMB experimental results. Figure $11 \mathrm{~b}$ shows the mechanical rotation angle that occurs in accordance with the rotation of the motor. One sawtooth wave occurs when the motor rotates once, and a straight line waveform is shown when the motor rotation stops. The maximum clamping force is generated and maintained at the time of the motor stopping, as can be seen from the wave form. A total of 19 rotations were carried out before the occurrence of the maximum clamping force, and the rotation speed was measured at about $2800 \mathrm{rpm}$.

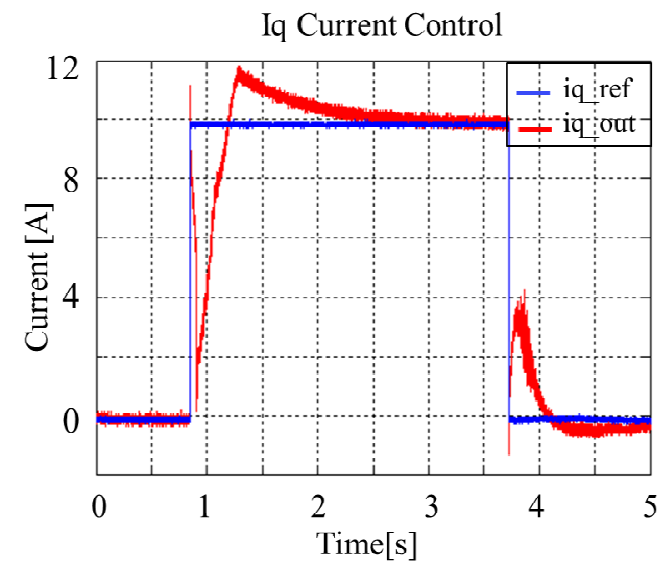

(a)

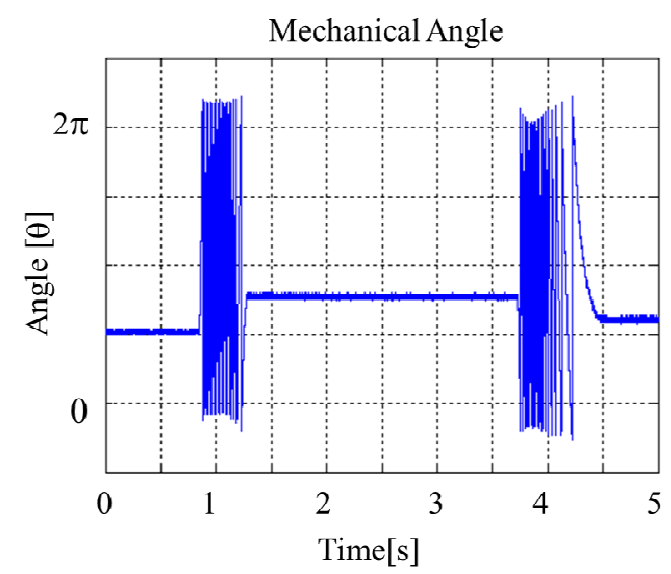

(b)

Figure 11. EMB experimental results: (a) Iq axis current control; (b) mechanical rotation angle.

As mentioned above, the maximum clamping force of the experimental result is $4 \%$ smaller than the design specifications of the HEMU-430X at $110 \mathrm{~km} / \mathrm{h}$, as shown in Figure 9. This paper suggests a PI controller which includes an anti-windup controller. Anti-windup controllers are used widely in industry to prevent the saturation phenomenon of integrators. Integrator saturation leads to a step response with a large overshoot and a high settling time. There has been a great deal of research on anti-windup PI control schemes. In this paper, the tracking back calculation scheme is applied to reduce the settling time and improve the clamping force. Figure 12 shows the anti-windup PI control schemes [19]. In the linear range, if $u$ and $v$ are the same, $e_{r}$ is applied to the integrator input. In the saturation range, $u$ and $v$ are different, at that time, $e_{r}-K_{p a} e_{f b}$ is applied to the integrator input. Usually, an anti-windup gain of $K_{p a}=1 / K_{p}$ is selected. Appropriate gain choice results in fast transient response, because the integrator is reset quickly. If the anti-windup gain value is too high, errors can cause input saturation.

Figure 13 shows the application of anti-windup controller in the EMB system. Input values are divided into a synchronous d-q axis frame. The output voltages of the three-phase inverter was limited by the control programing. In addition, anti-windup gain $K_{p a}$ was denoted to be $1 / K_{p}$. 


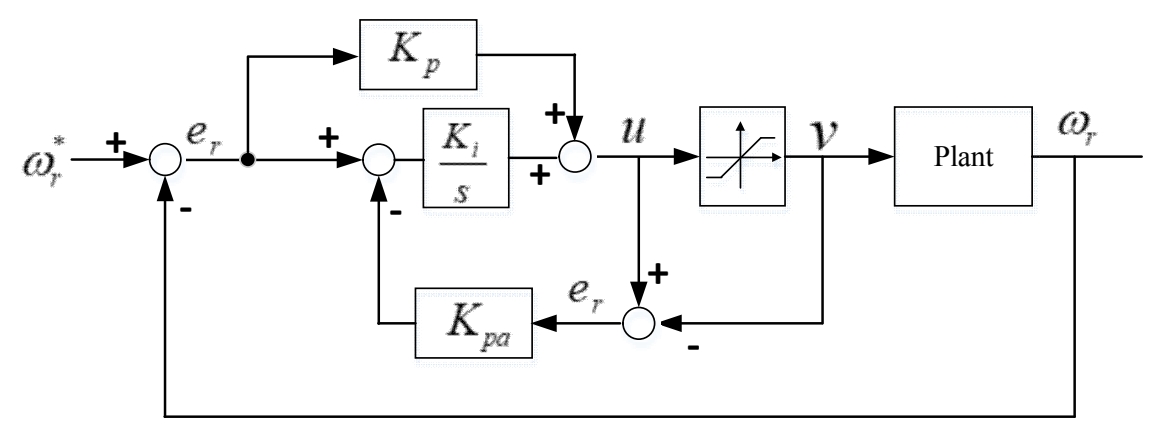

Figure 12. Anti-windup controller (tracking back calculation scheme).

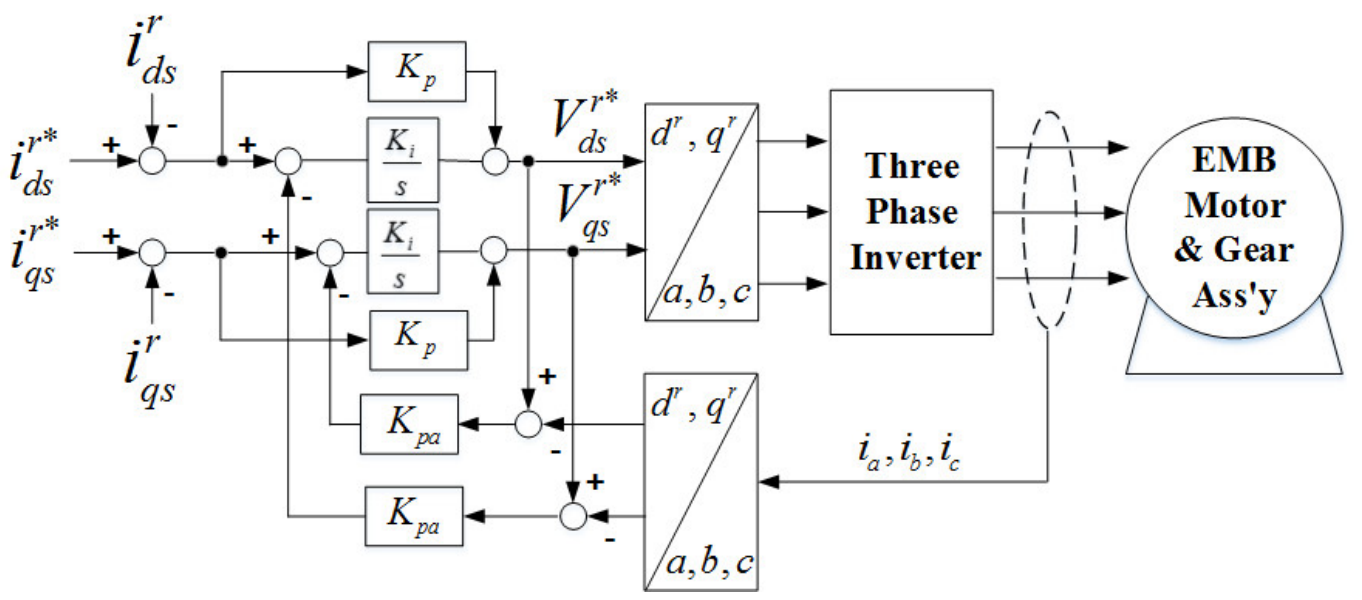

Figure 13. Concept diagram for proposed PI controller using anti-windup feedback control.

Figure 14 shows the experimental results for clamping force when an anti-windup controller is added. The current references for the synchronous $\mathrm{d}-\mathrm{q}$ axis frame of $0 \mathrm{~A}$ and $10 \mathrm{~A}$, respectively, were applied. As shown in Figure 14a, the maximum clamping force value was measured as being $54 \mathrm{kN}$, and overshoot did not occur at transient response. Figure $14 \mathrm{~b}$ shows the output latency time according to the input of the q-axis reference current, and it took $170 \mathrm{~ms}$. In comparison to Figure 10, the time taken to reach the maximum clamping force and the latency time increased by $90 \mathrm{~ms}$ and $120 \mathrm{~ms}$, respectively. It is thought that the response time was delayed due to the increase in the calculation time of the EMB inverter controller.

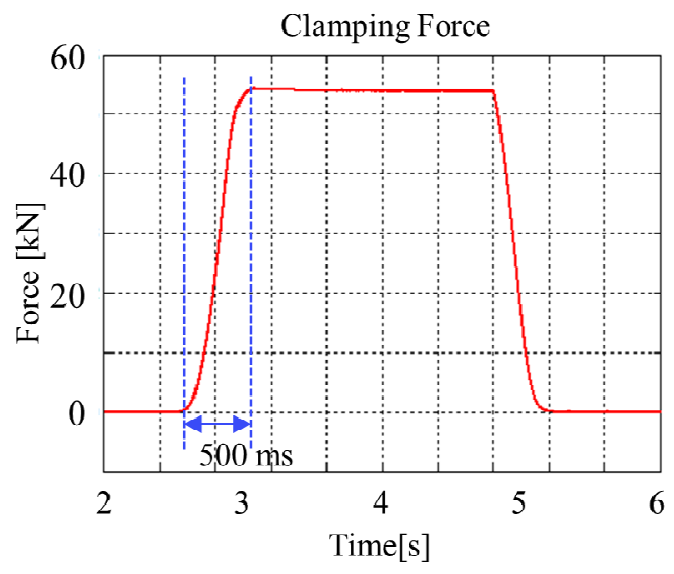

(a)

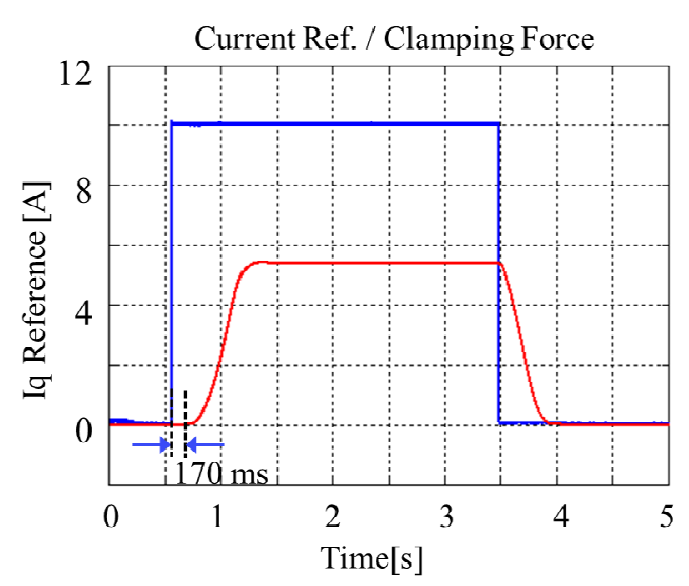

(b)

Figure 14. EMB experimental results using proposed control method: (a) clamping force; (b) response time of clamping force. 
Figure 15 shows the current control waveform at the time of the occurrence of maximum clamping force. Compared to Figure 11, the current of the q-axis increased by about $2 \mathrm{~A}$ under the motor stall state. However, the tracking performance to the reference current was faster by more than $1 \mathrm{~s}$. The sawtooth width under the transient response is different, because the rising time of Figure $15 \mathrm{~b}$ is $90 \mathrm{~ms}$ longer than Figure 11b. In addition, the angle values under the motor stall state are different in accordance with clamping force. If electric parts, especially the switching devices of inverters, are designed to have a current margin, this control method will not affect the EMB system. In addition, as shown in Figure 15b, under the motor stall state, the sustained performance of the clamping force was the same.

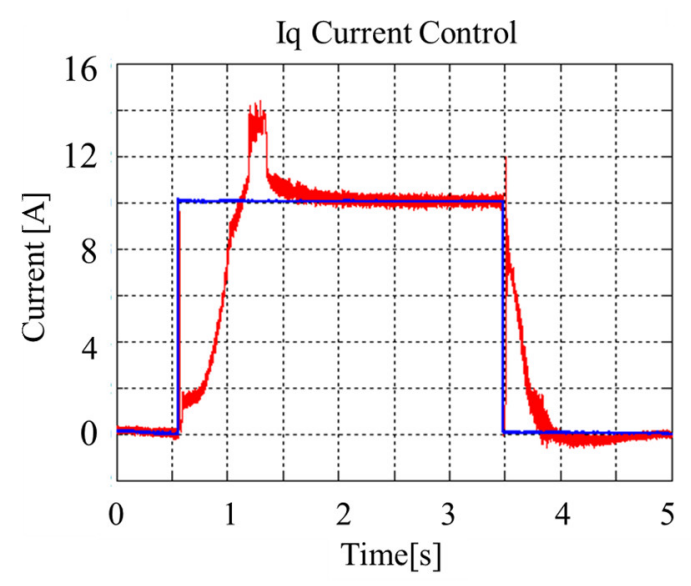

(a)

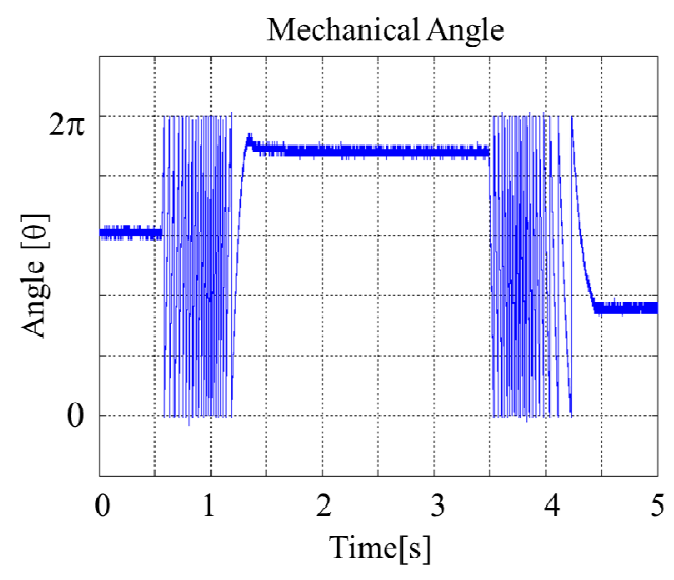

(b)

Figure 15. EMB test results: (a) Iq axis current control; (b) mechanical rotation angle.

Table 3 shows the experimental results for clamping force according to the synchronous frame current reference of the q-axis in the EMB and the braking steps corresponding to each operation speed of HEMU-430X in Figure 9. The braking force was divided into a total of 7 stages, and the clamping force output for each braking step, corresponding to each speed, was satisfied in all areas of speed through the adjustment of the synchronous-frame d-axis current reference for the EMB.

Table 3. Clamping force for current reference.

\begin{tabular}{ccccc}
\hline $\begin{array}{c}\text { Current } \\
\text { Reference }\end{array}$ & $\begin{array}{c}\text { Simulation Result of } \\
\text { Clamping Force } \mathbf{( k N )}\end{array}$ & $\begin{array}{c}\text { Experimental Results of } \\
\text { Clamping Force (kN) }\end{array}$ & $\begin{array}{c}\text { Braking Steps of } \\
\text { HEMU-430X }\end{array}$ & $\begin{array}{c}\text { Operation } \\
\text { Speed (km/h) }\end{array}$ \\
\hline 4 & 20.7 & 21.2 & 1 & 400 \\
5 & 25.8 & 26.0 & 2 & 350 \\
6 & 31.0 & 31.0 & 3 & 300 \\
7 & 36.2 & 37.6 & 4 & 230 \\
8 & 41.3 & 42.6 & 5 & 160 \\
9 & 46.5 & 48.5 & 6 & 110 \\
10 & 51.5 & 54.0 & 7 & 0 \\
\hline
\end{tabular}

\section{Conclusions}

This paper deals with Matlab/Simulink simulation and experimental results for the maximum clamping force for EMB. The PI current controller was applied to control clamping force. The maximum clamping force was improved by about $4.8 \%$ when the anti-windup controller was added to the PI current controller for the SPMSM control. The performance requirements are a maximum clamping force of $52 \pm 2 \mathrm{kN}$ and a response time of within $500 \mathrm{~ms}$. As a result, the EMB requirements were satisfied. In addition, the clamping force errors between the simulation and the experimental results were within $5 \%$ for each current reference. Braking outputs categorized into seven steps 
in accordance with operating speed for the HEMU-430X train are enabled by this EMB system. Although clamping force tracking performance was satisfied by the static experimental results, there was no consideration of the effects of dynamic test environments, such as thermal effects, vibration of the caliper, and parameter variations. In future works, an additional control algorithms will be needed, such as speed control, force control, gap compensation control and robust control of parameter variation.

Author Contributions: S.-I.S. provided supervision. S.-W.K. conceived the conceptualization of this paper. H.-K.O. performed investigation and validation. S.-K.B. implemented the main research, performed the simulation and experiment, wrote the paper and revised the manuscript as well. All authors contributed equally to the simulation analysis, experiment and result discussions.

Funding: This research was supported by a grant from R\&D Program (No. PK1801B2) of the Korea Railroad Research Institute, Republic of Korea.

Conflicts of Interest: The authors declare no conflict of interest.

\section{References}

1. Bannatyne, R.T. Advances and Challenges in Electronic Braking Control Technology; SAE Technical Paper; SAE: Warrendale, PA, USA, 1998. [CrossRef]

2. Sundar, M.; Plunkett, D. Plunkett, D. Brake-by-Wire, Motivation and Engineering-GM Sequel; SAE Technical Paper; SAE: Warrendale, PA, USA, 2006. [CrossRef]

3. Cheon, J.S. J.S. Brake by Wire System Configuration and Functions Using Front EWB (Electric Wedge Brake) and Rear EMB (Electro-Mechanical Brake) Actuators; SAE Technical Paper; SAE: Warrendale, PA, USA, 2010. [CrossRef]

4. Ahn, J.K.; Jung, K.H.; Kim, D.H.; Jin, H.B.; Kim, H.S.; Hwang, S.H. Analysis of a regenerative braking system for hybrid electric vehicles using an electro-mechanical brake. Int. J. Automot. Technol. 2009, 10, $229-234$. [CrossRef]

5. Atia, M.R.A.; Haggag, S.A.; Kamal, A.M.M. Enhanced electromechanical brake-by-wire system using sliding mode controller. J. Dyn. Syst. Meas. Control 2016, 138, 041003. [CrossRef]

6. Liang, B.; Zhu, Y.; Li, Y. Adaptive Nonsingular Fast Terminal Sliding Mode Control for Braking Systems with Electro-Mechanical Actuators Based on Radial Basis Function. Energies 2017, 10, 1637. [CrossRef]

7. Jo, C.; Hwang, S.; Kim, H. Clamping-force control for electromechanical brake. IEEE Trans. Veh. Technol. 2010, 59, 3205-3212. [CrossRef]

8. Ki, Y.H.; Lee, K.J.; Cheon, J.S.; Ahn, H.S. Design and implementation of a new clamping force estimator in electro-mechanical brake systems. Int. J. Automot. Technol. 2013, 14, 739-745. [CrossRef]

9. Lee, Y.O.; Jang, M.; Lee, W.; Lee, C.W.; Chung, C.C.; Son, Y.S. Novel clamping force control for electric parking brake systems. Mechatronics 2011, 21, 1156-1162. [CrossRef]

10. Eum, S.; Choi, J.; Park, S.-S.; Yoo, C.; Nam, K. Robust clamping force control of an electro-mechanical brake system for application to commercial city buses. Energies 2017, 10, 220. [CrossRef]

11. Hwang, W.; Huh, K. Fault detection and estimation for electromechanical brake systems using parity space approach. J. Dyn. Syst. Meas. Control 2014, 137, 014504. [CrossRef]

12. Kim, S.; Huh, K. Fault-tolerant braking control with integrated EMBs and regenerative in-wheel motors. Int. J. Automot. Technol. 2016, 17, 923-936. [CrossRef]

13. Hwang, W.; Han, K.; Huh, K. Fault detection and diagnosis of the electromechanical brake based on observer and parity space. Int. J. Automot. Technol. 2012, 13, 845-851. [CrossRef]

14. Han, K.-J.; Yang, I.-J.; Huh, K.-S. Current and force sensor fault detection algorithm for clamping force control of electro-mechanical brake. J. Inst. Control Robot. Syst. 2011, 17, 1145-1153. [CrossRef]

15. Ki, Y.-H.; Ahn, H.-S.; Cheon, J.S. Fault-Tolerant Control of EMB Systems; SAE Technical Paper; SAE: Warrendale, PA, USA, 2012; Volume 5, pp. 579-589.

16. Sho, M.; Park, K.; Park, M.; Kim, M. Development of a Fail-Safe Control Strategy for Electro-Mechanical Brake System; SAE Technical Paper; SAE: Warrendale, PA, USA, 2013. [CrossRef]

17. Kim, M.S.; Oh, S.C.; Kwon, S.J. Characteristic Test of the Electro Mechanical Brake Actuator for Urban Railway Vehicles. J. Korean Soc. Precis. Eng. 2016, 33, 535-540. [CrossRef] 
18. Rowan, T.M.; Kerhman, R.J. A new synchronous current regulator and an analysis of current-regulated PWM inverter. IEEE Trans. Ind. Appl. 1986, IA-22, 678-690. [CrossRef]

19. Shin, H.-B. New antiwindup PI controller for variable-speed motor drives. IEEE Trans. Ind. Electr. 1998, 45, 445-450. [CrossRef] 